\title{
TÉCNICA, CORPO E COISIFICAÇÃO: NOTAS DE TRABALHO SOBRE O TEMA DA TÉCNICA EM THEODOR W. ADORNO*
}

\author{
JaISON JOSÉ BASSANI ${ }^{* *}$ \\ Alexand de Fernandez $\bigvee_{A Z} Z^{* * *}$
}

\begin{abstract}
RESU M 0 : Trata-se aqui de umas notas de trabalho sobre o tema da técnica em Theodor W. Adorno. 0 ensaio Educação após Auschwitz e um conjunto de aforismos que compõem o livro M inima moralia são tomados como fontes principais, mas também como roteiro de investigação. As críticas de Adorno à técnica aparecem em vários registros e privilegiamos, nos marcos de nossa reflexão, as relacionados ao corpo e à produção da consciência, el ementos que se combinam diversamente nas obras pesquisadas, mas que encontram seu desiderato na crítica ao mundo administrado e aos destinos da subjetividade. N ossos resultados mostram que nas reflexões de Adorno o profundo processo de embrutecimento do humano e a supressão de quaisquer traços de particularidade aparecem intimamente relacionados com 0 crescente processo de tecnificação, o que por sua vez engendra uma certa pedagogia dos gestos e do corpo. Sugere-se, neste sentido, que a técnica mais refinada não necessariamente leva a um aumento das possibilidades humanas, mas, talvez encaminhe, tendencialmente, a uma escravização do corpo por meio da incorporação dos processos reificadores da tecnificação.
\end{abstract}

Palavras-chave: T écnica. Coisificação. Corpo. Teoria crítica. Theodor W. Adorno.

\footnotetext{
* 0 presente texto apresenta resultados parciais do projeto Teoria Crítica, Racionalidades e Educação, financiado pelo cN Pq.

** D outorando no Programa de Pós-graduação em Educação da U niversidade Federal de Santa Catarina (UFSC) e bolsista da CAPES. E-mail: jaisonbassani@uol.com.br

*** Doutor em Ciências H umanas e Sociais e professor do D epartamento de M etodologia de Ensino e do Programa de Pós-Graduação em Educação da uFsc. E-mail: al exfvaz@pq.cnpq.br
} 
Técnica, corpo e coisificação: notas de trabalho sobre o tema da técnica...

\section{TECHNIQUE, BODY AND REIFICATION: Work notes about this theme by Theodor W. Adorno}

ABST RACT : This paper brings some work notes on the topic of technique by Theodor W. Adorno. The essay Education after Auschwitz and some of the aphorisms in M inima moralia are taken as main sources, and also as part of an investigation plan. Adorno's criticism of technique appears in several parts of his work. In our reflection, we have prioritized criticism related to the body and the production of conscience, as they are elements which have different combinations in the researched texts, but a common goal in the criticism of the administered world and the destiny of subjectivity. O ur results show that, in Adorno's reflections, the deep process of human brutalization and the suppression of any particularity traits are closely related to the growing technification process, which engenders a certain gesture and body pedagogy. It's suggested, in that sense, that the most refined techniques do not necessarily increase human possibilities. $\mathrm{O}$ the contrary, they may lead to body slavery through the incorporation of technifying reification processes.

Key words: Technique. Reification. Body. C ritical theory. Theodor W. Adorno.

\section{Introdução}

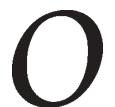

tema da técnica foi alvo de reflexões de parte importante de uma geração de pensadores que viveu os horrores do breve século xx. D e Veblen a Gramsci, passando por O rtega y Gasset, Spengler, G ehlen e H eidegger, e chegando até $D$ errida, a crítica à técnica - mas também sua celebração - ocupou e ainda ocupa lugar de destaque no pensamento contemporâneo.

D ela também se ocuparam os pensadores associados à "primeira" Escola de Frankfurt, não apenas aquele que é mais facilmente relacionado à temática, H erbert M arcuse (1966, 1999, entre outros), mas também Theodor W. Adorno, para o qual a pergunta sobre a técnica - se quisermos empregar uma expressão cara a M artin H eidegger - esteve no centro da crítica ao contemporâneo. Em Dialética do esclarecimento, clássica obra escrita com M ax H orkheimer (H orkheimer \& Adorno, 1985), lêse que o progresso e a cultura ocidental devem ser entendidos pelo movimento de passagem do estágio do mito para o do esclarecimento que, 
por sua vez, retorna violentamente ao estágio mitológico, produzindo um deslocamento regressivo cujo conteúdo será novamente a dominação e a barbárie. A técnica seria o modus operandi desse processo que objetiva 0 método, o cálculo e a exploração (Brüseke, 2001).

A equação entre técnica e progresso leva tanto H orkheimer e Adorno quanto Benjamin e $\mathrm{M}$ arcuse a não poder desvincular desenvolvimento técnico e/ou científico dos seus fins, já que o aumento de habilidades e conhecimentos não necessariamente significaria o progresso da humanidade como gênero. Segundo Adorno (1995b, p. 40), “(...) é impossível aceitar qualquer progresso como se a humanidade já existisse como tal e, portanto, pudesse progredir. Pelo contrário, o progresso seria a geração de humanidade (...)". M omentos diferentes, progressos técnico e humano estariam em estreita relação porque o primeiro seria condição para a realização do segundo (M arcuse, 2001; Adorno, 1995b). N o entanto, como advertem H orkheimer e Adorno (1985, p. 49), "à medida que cresce a capacidade de eliminar duradouramente toda a miséria, cresce também desmesuradamente a miséria como antítese da potência e impotência". 0 progresso converte-se no seu contrário:

Parece que enquanto o conhecimento técnico expande o horizonte da atividade e do pensamento humanos, a autonomia do homem como indivíduo, a sua capacidade de opor resistência ao crescente mecanismo de manipulação das massas, o seu poder de imaginação e o seu juízo independente sofreram aparentemente uma redução. 0 avanço dos recursos técnicos de informação se acompanha de um processo de desumanização. Assim, 0 progresso ameaça anular o que se supõe ser o seu próprio objetivo: a idéia de homem. (H orkheimer, 2000, p. 9-10)

N o processo de dominação perene da natureza, a técnica, como uma espécie de segunda natureza humana, engendra um profundo esquecimento do sofrimento, da nossa própria natureza, provindo sua força justamente dessa cegueira. Esse esquecimento do sofrimento humano não é outro senão o próprio percurso de constituição do sujeito esclarecido e, de forma mais geral, do pensamento racional.

Segundo a conhecida argumentação de H orkheimer e Adorno, a constituição de eu (ego) durável e idêntico a si mesmo só teria sido possível na medida em que o humano se constituiu na separação com a natureza, estranhando-a para poder dela apoderar-se. $\mathrm{N}$ o entanto, como condição para o domínio da natureza externa a si, teria sido preciso que 
T écnica, corpo e coisificação: notas de trabalho sobre o tema da técnica...

o eu esclarecido em formação dominasse - e para isso esquecesse, alienasse - o seu compartilhamento com a natureza, a natureza interna, o corpo. 0 próprio conhecimento erigido dessa dominação, a capacidade de manipulação técnica da natureza, acabaria reagindo sobre a subjetividade que se formou nessa atividade dominadora. A constituição original de um eu identificado somente consigo mesmo resultaria da dissolução, do solapamento daquele vínculo simpático - mas, ao mesmo tempo, homicida - com a natureza, que o sacrifício ritual da razão subjetiva pretendia conservar. A história da civilização, do sujeito e, portanto, da própria H istória emergiria de um ato de violência demarcado pelo seu constante esquecimento contra a natureza e o próprio homem.

$\mathrm{N}$ as próximas páginas elaboramos algumas notas de trabal ho sobre o tema da técnica em Theodor W. Adorno. Para tanto, tomamos 0 texto Educação após Auschwitz - uma espécie de síntese, mas ao mesmo tempo especificação para o campo educacional, de Dialética do esclarecimento - e um conjunto de aforismos que compõem o livro M inima moralia, como fontes principais, mas também como roteiro de investigação. As críticas de Adorno à técnica aparecem em vários registros e privilegiamos, nos marcos de nossa reflexão, as relacionadas ao corpo e à produção da consciência, el ementos que se combinam diversamente nas obras pesquisadas, mas que encontram seu desiderato na crítica ao mundo administrado e aos destinos da subjetividade.

Procuramos, com isso, aproximar-nos do tema da educação em Adorno por meio de um leitmotiv que catalisa de forma dialética sua re flexão sobre o contemporâneo. Com ele Adorno não se deixa levar pela simples condenação peremptória, mas guia-se pela força contraditória que a técnica, como expressão iluminista, faz conhecer sobre a sociedade contemporânea.

\section{Tecnificação, produção da consciência, corpo}

0 tema da técnica aparece de forma singular no texto-conferência Educação após Auschwitz (Adorno, 1995a). N ele é interessante atentar para a passagem em que é destacado o caráter fetichista daquela e sua relação com o esporte - uma forma contemporânea de organização da corporalidade - , com o qual, afirma Adorno, ela teria afinidade (idem, ibid., p. 132). 0 esporte, ao mesmo tempo em que poderia ter um efeito contrário 
à barbárie e ao prazer em infringir violência, permitiria, paradoxalmente, fomentar a agressão e o sadismo. A sociedade contemporânea, na qual a técnica ocupa uma posição decisiva - inclusive do ponto de vista da distribuição da energia psíquica que corresponde ao tipo societário em vigor -, acabaria gerando pessoas tecnológicas. Isso teria uma racionalidade positiva, destaca Adorno: "Em seu plano mais restrito elas [as pessoas] serão me nos influenciáveis, com as correspondentes conseqüências no plano geral" (idem, ibid., p. 132). H averia, no entanto, na relação contemporânea com a técnica algo de exagerado, irracional, patogênico, vinculado ao que 0 autor chama de véu tecnológico. N as suas palavras, "os homens inclinam-se a considerar a técnica como sendo algo em si mesma, um fim em si mesmo, uma força própria, esquecendo que ela é a extensão do braço dos homens" (idem, ibid.). Esse tipo de relação com a técnica se tornaria possível porque os meios - a técnica é um deles ${ }^{1}$ - são fetichizados, uma vez que os fins a que se dirigem, ou seja, uma vida humana digna, encontram-se encobertos e desconectados da consciência das pessoas.

Essas considerações ganham ainda mais relevância se atentarmos para o contexto em que aparecem no texto-conferência. Adorno inscreve o comentário sobre a técnica - assim como aquele em relação ao esporte - naquilo que chama de "(...) velho e bom caráter autoritário" (Adorno, 1995a, p. 127). Para ele, os tipos característicos de Auschwitz apresentariam algo presumivelmente novo. Eles representariam a identificação cega com o coletivo, ao mesmo tempo em que seriam talhados para manipular as massas. Ao poder cego da coletivização, perante 0 qual as pessoas perdem qualquer resquício de individualidade e autodeterminação, seria preciso contrapor-se como forma de enfrentar o perigo, sempre potencialmente presente, de que a barbárie se repita, fortalecendo a resistência ante ela por meio do esclarecimento acerca dos problemas decorrentes dos processos de coletivização - sejam eles manifestos na organização escolar, esportiva, política ou, em sentido mais estrito, nos esquemas da indústria cultural. 0 ponto de partida para essa tarefa poderia estar na refutação do

(...) sofrimento que os coletivos infligem no começo a todos os indivíduos que se filiam a eles. Basta pensar nas primeiras experiências de cada um na escola. É preciso se opor àqueletipo de folk-ways, hábitos populares, ritos de iniciação de qualquer espécie, queinfligem dor física- muitas vezes insuportável - a uma pessoa como preço do direito de ela se sentir um filiado, um 
Técnica, corpo e coisificação: notas de trabalho sobre o tema da técnica...

membro do coletivo. A brutalidade de hábitos tais como trotes dequalquer ordem, ou quaisquer outros costumes arraigados desse tipo, é precursora imediata da violência nazista. (Adorno, 1995a, p. 127-128)

Para Adorno, tais hábitos comuns nos processos de coletivização² entre eles os esportes - estão vinculados a um ideal que desempenha um papel relevante na educação tradicional, a severidade. U ma educação baseada na força e na disciplina irrefletida seria completamente equivocada e extremamente perigosa. $N$ as suas palavras, "a idéia de que a virilidade consiste num grau máximo da capacidade de suportar dor de há muito se converteu em fachada de um masoquismo que - como mostrou a psicologia se identifica com muita facilidade ao sadismo" (1995a, p. 128) Dito de outra forma, o ser duro desse tipo de educação significaria, na verdade, indiferença à dor em geral. I sso quer dizer que quem é duro, severo consigo mesmo, adquire o direito de sêlo com os outros, vingando-se da dor cujas manifestações precisou ocultar e reprimir, refazendo o círculo infernal do sadomasoquismo.

D iz Adorno que pessoas que se enquadram cegamente em coletivos convertem a si em algo como "um material", eliminando quaisquer traços de autodeterminação. A isso corresponderia a disposição de tratar os outros como massa amorfa. Para os que se comportam dessa maneira, Adorno (1995a, p. 129) utiliza a já citada expressão caráter manipulador, que se distinguiria

(...) pela fúria organizativa, pela incapacidade total de levar a cabo experiências humanas diretas, por um certo tipo de ausência de emoções, por um realismo exagerado. A qualquer custo ele procura praticar uma pretensa, embora delirante, Real politik. $\mathrm{N}$ em por um segundo sequer ele imagina o mundo diferente do que ele é, possesso pela vontade de doing things, de fazer coisas, indiferente ao conteúdo de tais ações. Ele faz do ser atuante, da atividade, da chamada effi ci ency enquanto tal, um culto, cujo eco ressoa na propaganda do homem ativo.

É notável a preocupação que Adorno destina ao tema da violência, ${ }^{3}$ certamente uma herança dos horrores nazistas, mas também a marca de uma sensibilidade singular, cuja matriz operacional teria origem ainda na infância, como se lê em M inima moralia. N esse quadro se encontra uma passagem de uma conferência escrita e pronunciada alguns anos antes de Educação após Auschwitz: 
$\mathrm{N}$ o sentido deuma pedagogia contra o preconceito seria importante encorajar as amizades individuais e não ironizá-las ou difamá-las; ao contrário, tanto quanto possível, trabalhar contra as gangues fanfarronas e outros grupos do mesmo tipo, especialmente quando eles buscam poder. A estrutura da formação de gangues na escola em geral é um fenômeno central. Como em um microcosmos desenha-se o problema detoda a sociedade em geral. (Adorno, 1971, p. 124-125)

Também é digno de nota que um tema caro ao texto anteriormente referido apareça na seqüência do acima, vinculando violência, formação de Cliquen (gangues) e a dupla hierarquia que compõe a escola, ela também vinculada ao predomínio da reificação e do fetichismo da técnica como provedora da força física:

\begin{abstract}
Evidentemente correspondem estas gangues a um tipo de hierarquia secreta que se contrapõe à hierarquia oficial da escola, regulada pelo desempenho. N elas são honorificadas inteiramente outras qual idades - força física, um tipo específico de vel ocidade e assemel hados - apenas para o dizermos de forma breve. N esse contexto é preciso remeter-se ao perigo das organizações, que da escola se aproximam organicamente e na qual al gumas crianças, mas não outras, incorporam-se. D aí se origina facilmente um princípio de exclusão. (Idem, ibid.)
\end{abstract}

N o quadro das condições de produção da consciência reificada, Adorno inscreve seus já mencionados comentários sobre a fetichização da técnica, advertindo que não se saberia com certeza como esta se estrutura na psicologia individual e onde seria o limiar entre uma relação racional com a técnica e sua supervalorização, "(...) que leva, em última análise, quem projeta um sistema ferroviário para conduzir as vítimas a Auschwitz com maior rapidez e fluência, a esquecer o que acontece com essas vítimas em Auschwitz" (Adorno, 1995a, p. 133). ${ }^{4}$ Para ele, no caso de pessoas com tendências à valorização exagerada da técnica, trata-se de indivíduos incapazes de estabelecer uma relação libidinal com outras pessoas, ou seja, incapacitadas de amar. Adorno afirma ter se deparado com muitas evidências empíricas no que diz respeito a essa assertiva, referindo-se à famosa pesquisa que coordenou sobre as personalidades preconceituosas e vinculadas ao autoritarismo (T he authoritarian personality), realizada entre os anos 1947-1949 durante o exílio nos Estados Unidos. Relatando o caso de um sujeito que participou da investigação, afirma: 
T écnica, corpo e coisificação: notas de trabalho sobre o tema da técnica...

U m sujeito experimental - ea própria expressão já é do repertório da consciência coisificada - afirmava de si mesmo: "I like nice equipment" (Eu gosto de equipamentos, de instrumentos bonitos), independentemente dos equi pamentos em questão. Seu amor era absorvido por coisas, máquinas enquanto tais. 0 perturbador - porque torna tão desesperançoso atuar contrariamente a isso - é que esta ten dência de desenvolvimento se encontra vinculada ao conjunto da civilização. Combatêlo significa o mesmo que ser contra o espírito do mundo (...). (1995a, p. 133)

Todas essas questões ganham importância por conta da crítica de Adorno à frieza burguesa, ${ }^{5}$ destacando que uma educação contra o preconceito deve fomentar 0 calor das amizades individuais entre as crianças como contraponto aos processos de coletivização (Adorno, 1971).

Essa relação entre técnica e coisificação aparece também em outras passagens da obra de Adorno, como nas M inima moralia (Adorno, 1993). $\mathrm{N}$ esse livro encontramos, em meio a profundas reflexões sobre as vicissitudes do sujeito e o aniquilamento da particularidade no mundo contemporâneo, uma série de aforismos nos quais o tema da técnica emerge com força arrebatadora. Eles se referem, especialmente, a uma certa educação dos gestos humanos engendrada pela crescente tecnificação, a uma (des)subjetivação ancorada no corpo. Tal processo conduziria, segundo Adorno, à perda da delicadeza e da civilidade, a um embrutecimento dos gestos, como pode ser lido no aforismo N ão bater à porta:

A tecnificação torna, entrementes, precisos e rudes os gestos, e com isso os homens. Ela expulsa das maneiras toda hesitação, toda ponderação, toda civilidade, subordinando-as às exigências intransigentes e como que a-históricas das coisas. D esse modo, desapren de-se a fechar uma porta de maneira silenciosa, cuidadosa e, no entanto, firme. As portas dos carros e das geladeiras são para serem batidas, outras têm a tendência a fechar-se por si mesmas, incentivando naqueles que entram o mau costume de não olhar para trás, de ignorar o interior da casa que os acolhe. $\mathrm{N}$ ão faz mais justiça ao novo tipo de homem, se não se tem consciência daquilo que está incessantemente exposto pelas coisas do mundo ao seu redor, até em suas mais secretas inervações. 0 que significa para o sujei to que não existam maisjanelas que se abram como asas, mas somente vidraças de correr para serem bruscamente impelidas? Q ue não existam mais trincos de portas, e sim maçanetas giratórias, que não existam mais vestíbulos, nem soleiras dando para a rua, nem muros ao redor do jardim? E qual motorista que já não foi tentado pela potência do motor de seu veículo a atropelar a piolhada da rua, pedestres, crianças e ciclistas? N os movimentos que as máquinas exigem 
daquel es que delas se servem localizam-se já a violência, os espancamentos, a incessante progressão aos solavancos das brutalidades fascistas. N 0 deperecimento da experiência, um fato possui uma considerável responsabilidade: que as coisas, sob a lei de sua pura funcionalidade, adquirem uma forma que restringe o trato delas a um mero manejo, sem tolerar um só excedente - seja em termos de liberdade de comportamento, seja de independência da coisa - que subsista como núcleo da experiência porque não é consumido pelo instante da ação. (1993, p. 33)

Esse processo de coisificação mediado pela técnica, que parece tornar as pessoas iguais às máquinas e transferir a violência originalmente nelas radicada para aquelas, é destacado mais uma vez no aforismo D evagar e sempre. N ele, Adorno (1993, p. 102) referese ao andar apressado das pessoas nas ruas, produzido, em grande medida, pela incorporação do culto à velocidade técnica que teria no fascínio pelos carros e pela potência dos seus motores - mas também pelas estradas e rodovias - uma expressão mais magníloqua. N o entanto, essa incorporação é ela própria fruto da violência arcaica do ser humano contra a natureza, tanto externa quanto, especialmente, interna à sua própria constituição, movimento que não cessa de dar testemunho:

Talvez se oculte no culto da vel ocidade técnica, como no esporte, o impulso para dominar aquele terror das correrias, desviando-as do próprio corpo e, ao mesmo tempo, reenvidando-as de forma soberana: o triunfo do marcador de quilômetros que vai subindo vem aplacar de maneira ritual a angústia do fugitivo. M as quando se grita para al guém: "C orre!", quer se trate da criança que deve apanhar para sua mãe a sacola esqueci da no primeiro andar, ou do prisioneiro a quem a escolta manda fugir para ter um pretexto para assassiná-lo, faz-se ouvir a violência arcaica que de outro modo guia imperceptivel mente cada passo. (Adorno, 1993, p. 102)

Como em Educação após Auschwitz, vemos uma explícita referência ao esporte e sua profunda relação com a técnica, que aparece também em vários outros momentos da obra de Adorno, entre eles o ensaio 0 ataque de Veblen à cultura (Adorno, 1997a), no qual o autor, ao destacar a posição de T horstein Veblen ${ }^{6}$ - que interpretara as práticas esportivas, em todos os seus níveis, como manifestações arcaicas e violentas que expressam o espírito predatório do ser humano, mas também como pseudoatividades responsáveis pelo apaziguamento pulsional -, afirma que esta poderia ser aperfeiçoada. A psicologia racionalista de Veblen o teria impedido de ver o mais importante, o momento masoquista do esporte: 
Técnica, corpo e coisificação: notas de trabalho sobre o tema da técnica...

“(...) ao esporte pertence não apenas o impulso à violência, mas também a suportá-la e tolerá-la" (idem, ibid., p. 80). N esse quadro, Adorno dirá que o esporte é menos um resquício de antigas formas de sociedade, como entendera Veblen, mas também, e principalmente, uma adaptação inicial a essa sua nova e ameaçadora forma contemporânea: a sociedade da tecnologia. 0 esporte seria uma forma de promover a adaptação do ser humano à maquinaria, de tal forma que ele a incorporaria, desaparecendo a diferença entre si e a máquina:

O esporte moderno, pode-se dizer, procura devolver ao corpo (Leib) uma parte das funções que dele a máquina subtraiu. M as o esporte pretende inexoravel mente inscrever os homens ao serviço da maquinaria. Ele assemelha, tendencial mente, o corpo à maquina. I sso faz com que o esporte adentre o reino da não-liberdade, onde quer que seja realizado. (Adorno, 1997 a, p. 80) ${ }^{7}$

I mporta ressaltar ainda outro elemento que é central nesses aforismos das M inima moralia até aqui destacados: que a relação de pura funcionalidade estabelecida com as coisas, que não deixa margem para qualquer expressão de liberdade e autonomia do indivíduo, conduz inevitavelmente à perda de uma das bases da constituição do sujeito: a experiência (Erfahrung).

\section{Vida danificada e declínio da experiência: técnica eindústria cultural}

O tema da experiência, assim como outros presentes em várias passagens da M inima moralia e mesmo em outras obras, é um dos vários tributos que Adorno paga a Walter Benjamin. Também para este os processos de tecnificação dos gestos e dos sentidos produzidos pelo ritmo da produção industrial, pelo avanço da técnica e pela complexificação urbana das grandes metrópoles, com seus desafios e ritmos cada vez mais acelerados, resultarão na estruturação de uma nova sensibilidade. Benjamin (1997) destacou que nas ruas das grandes cidades, nas quais o ritmo em meio à multidão é acelerado e 0 choque com os transeuntes é quase inevitável, os sentidos, especialmente o olhar, ${ }^{8}$ já não mais reconhecem, mas respondem, da mesma forma que os movimentos do corpo devem, antes de tudo, defender. A essa nova sensibilidade, gestada pelos avanços da técnica, não corresponde mais a experiência (Erfahrung), mas a vivência do choque (Chockerlebnis). 
0 tema do declínio da experiência - e da narrativa, forma de comunicação par excellence daquela - aparecerá mais uma vez no aforismo Longe dos tiros (Adorno, 1993). N esse pequeno texto bastante denso, escrito em outubro de 1944 - a data aqui não é menos importante -, o emprego da técnica aparece mais uma vez relacionado ao estreitamento da experiência, porém não mais diretamente em conexão com 0 desenvolvimento das forças produtivas e com o embrutecimento dos gestos na vida cotidiana, mas sim com uma situação limítrofe: a capacidade de destruição da maquinaria de guerra. Adorno refere-se a uma completa inadequação do corpo humano às batalhas entre máquinas, tornando impossível a experiência propriamente dita. Retomando uma tópica presente no início dos ensaios Experiência e pobreza e 0 narrador, ambos de Benjamin (1985), Adorno destaca o fato de aqueles que retornam da Segunda Guerra M undial serem incapazes de narrar a "sucessão intemporal de choques" por eles vivenciados - e não mais experienciados:

$\mathrm{N}$ inguém seria capaz de narrá-las [as batal has entre máquinas], tal como ainda era possível fazêlo a propósito das batal has do general de artilharia Bonaparte. 0 longo intervalo entre o surgimento de memórias da guerra e a conclusão da paz não é casual: ele testemunha quão penosa é a reconstrução da lembrança, a qual, em todos aqueles livros, permaneceligada a uma certa impotência e até mesmo a algo deinautêntico, pouco importando por quais horrores os narradores passaram. A Segunda G uerra, porém, está tão distante da experiência quanto o funcionamento de uma máquina dos movimentos do corpo humano, o qual só em estados patológicos se assemelha àquele. (Adorno, 1993, p. 46)

0 utro ponto importante presente nesse aforismo, relacionado ao tema da técnica, à perda da experiência e à indútria cultural - outro tributo a Benjamin -, refere-se à estetização da guerra promovida pelos modernos meios de comunicação, algo que, embora Adorno estivesse se referindo à Segunda Guerra M undial, pode, sem muitos exageros, ser facilmente percebido nos "espetáculos" televisivos da Guerra do G olfo, em 1991, e na recente Guerra do I raque, com hora e local marcados para acontecer, como um programa de "entretenimento", como os esportivos e de auditório:

0 completo encobrimento da guerra por meio da informação, da propaganda e dos comentários, a presença de operadores filmando nas primeiras linhas dostanques e a morteheróica dos repórteres de guerra, a mistura confusa de esclarecimento manipulador da opinião pública e ação inconsciente, tudo 
Técnica, corpo e coisificação: notas de trabalho sobre o tema da técnica...

isso é uma outra expressão para o definhamento da experiência, o vácuo entre os homens e sua fatalidade, no qual consiste propriamente a fatalidade. A cópia calcificada e reificada dosacontecimentos acaba, por assim dizer, por substituir estes mesmos. 0 s homens são rebai xados a atores de um monstruoso documentário, para o qual [não] há mais espectadores, pois todos, até o último, tomam parte na ação que se passa na tela. (I dem, ibid.)

A relação entre indústria cultural e técnica aparece novamente nas M inima moralia nos aforismos Jantar de gala e Leilão (Adorno, 1993, p. 103-105). N o primeiro, Adorno refere-se a um dos esquemas-chave pelo qual procede a indústria cultural, a repressão pulsional (H orkheimer \& Adorno, 1985, p. 130). Esse mecanismo está associado à oferta incessante de produtos que, ao serem apresentados como "novidades", insuflam nas pessoas a falsa expectativa de que seus desejos serão finalmente atendidos - o "novo o computador", o "modelo de carro mais potente", a "nova dieta milagrosa", a "nova modalidade de ginástica" - , quando, na verdade, não passam da eterna repetição do mesmo, do sempre igual:

Pode-se aprender muito sobre o atual entrelaçamento, entre progresso eregressão, com o conceito de possibilidades técnicas. 0 s procedimentos mecânicos de reprodução desenvolveram-se independentemente do que deve ser produzido e adquiriram autonomia... Ao progresso técnico responde 0 desejo obstinado e estreito de não comprar nenhum encalhe, de não ficar para trás no processo de produção desenfreado, não importa o sentido do que é produzido. Ir atrás dos outros, atropelar-se, fazer filas, tudo isso substitui por toda parte as necessidades de certo modo racionais. A rai va que se tem de uma composição radical, moderna demais, não émuito menor do que a que se tem em rel ação a um filme que já está há três meses em cartaz, ao qual as pessoas preferem a qual quer preço o mais recente, embora não se diferencie em nada daquele. (Adorno, 1993, p. 103)

O conceito de possibilidades técnicas, naquilo que se relaciona com certa banalização dos artefatos - dada também pela forma mercadoria que faz equivaler diferenças - , entre eles os culturais, também aparece no supracitado aforismo Leilão, no qual Adorno critica a eliminação do luxo não pelo fato de o desenvolvimento da técnica ter democratizado 0 acesso a ele, mas, pelo contrário, por ter elevado o nível comum:

A técnica desenfreada elimina o luxo, mas não declarando que o privilégio é um direito humano, e sim cortando, pela el evação geral do standard, a possibilidade de se satisfazer. 0 trem rápido, que em três noites e dois dias 
atravessa com en orme vel ocidade o continente, éum verdadeiro milagre, mas a viagem nele nada tem do esplendor desaparecido do train bleu (...). $M$ as essa promessa de felicidade no luxo pressupõe, por outro lado, o privilégio, a desigualdade econômica, a própria sociedade que se apóia na fungibilidade. Eis por que o qualitativo se torna, ele próprio, um caso especial da quantificação, o não-fungível, fungível, o luxo, conforto e, por fim, em gadget sem sentido. (Idem, ibid., p. 104-105)

Além da eliminação de quaisquer outros elementos que não estejam vinculados à pura funcionalidade ${ }^{9}$ os produtos erigidos no âmbito da indústria cultural pouco ou nada se diferenciam, objetivamente, uns dos outros:

(...) as vantagens do C adilac sobreo C hevrolet são tão maiores quanto mais caro ele custa, mas essa superioridade - ao contrário daquela do velho Rolls Royce - resulta ela própria de um planejamento integral, que equipa aquele com melhores cilindros, parafusos e acessórios, este com piores, sem que nada seja al terado no esquema básico da produção em massa: seriam necessárias apenas pequenas modificações na produção para transformar um Chevrolet num Cadilac. (Adorno, 1993, p. 104)

N estas últimas citações das M inima moralia, não podemos deixar de observar uma profunda relação com os mecanismos da indústria cultural e da produção da falsa mimesis que emerge como fungibilidade universal e inespecífica, tal como foram descritos por H orkheimer e Adorno (1985). A questão está relacionada àquilo que os autores consideram um dos mecanismos centrais da indústria cultural e que foi citado al guns parágrafos atrás: a repressão pulsional. A indústria cultural logra os seus consumidores porque a promessa de gratificação pulsional pela compra e pelo consumo das suas mercadorias é adiada indefinidamente, já que sua satisfação significaria o seu próprio fim. Ao contrário da arte autêntica, que apresenta a renúncia imediata das pulsões como algo negativo e que de certa forma revoga a humilhação da pulsão, salvando aquilo a que se renuncia como algo mediado, a indústria cultural reprime essas pulsões:

Eis o segredo da sublimação estética: apresentar a satisfação como uma promessa rompida. A indústria cultural não sublima, mas reprime. Expondo repetidamente o objeto de desejo, o busto do suéter e o torso nu do herói esportivo, ela apenas excita o prazer preliminar não sublimado que o hábito da renúncia há muito mutilou e reduziu ao masoquismo. 
Técnica, corpo e coisificação: notas de trabalho sobre o tema da técnica...

N ão há qual quer situação erótica que não junte à al usão e à excitação a indicação precisa de quejamais se deve chegar a esse ponto. (H orkheimer \& Adorno, 1985, p. 131)

0 utro ponto refere-se à presença de certa hierarquização dos produtos oferecidos pelos seus diversos ramos no que diz respeito à qualidade. H orkheimer e Adorno destacam que as distinções entre os filmes de classe " $A$ " ou " $B$ " ou entre os carros mais caros ou mais baratos - diríamos, atualmente, "populares" ou "seminovos" - não estão relacionadas diretamente com seu conteúdo, mas, sobretudo, com a classificação, organização e computação estatísticas dos consumidores: "C ada qual deve se comportar, como que espontaneamente, em conformidade com seu level, previamente caracterizado por certos sinais, e escolher a categoria dos produtos de massa fabricados para seu tipo" (idem, ibid., p. 116).

Ainda no que se refere à relação entre as anotações de Adorno nos aforismos Jantar de gala e Leilão, especialmente ao caráter discricionário do luxo e aos mecanismos da indústria cultural, talvez se possa destacar um terceiro ponto: a união dos domínios superior e inferior da arte, que outrora eram separados e agora se vêem unidos à força. H orkheimer e Adorno destacam que o entretenimento já era prática corrente muito tempo antes do predomínio da indústria cultural. D esde o início da civilização ocidental moderna havia, ao lado da arte séria, erudita - como expressão da promessa de felicidade e/ou do sofrimento ocultado - , uma outra, mais popular, a arte leve, que supria exatamente a função de entretenimento que a cultura mercantilizada exerce no nosso tempo. No entanto, no âmbito da indústria cultural, o que ocorre é uma absorção planejada e intencional da arte leve pela arte séria e vice-versa, sempre a serviço dos objetivos de lucratividade e manutenção/ampliação do controle social sobre os indivíduos (idem, ibid., p. 126-127; D uarte, 2002). Segundo Adorno (1978, p. 287-288):

Ela[a indústria cultural] força a união dos domínios, separados há milênios, da arte superior e da arte inferior. Com prejuízo de ambos. A arte superior vê-se frustrada de sua seriedade pela especulação sobre o efeito; a inferior perde, por meio de sua domesticação civilizadora, o elemento de natureza resistentee rude, quelhe era inerente enquanto o controlesocial não era total.

Em outras palavras, pode-se dizer que essa união, assim como a ele vação geral do padrão standard produzida pela tecnificação, desmancha 
progressivamente a linha divisória entre cultura e barbárie (D uarte, 1997), algo que Adorno sintetizou com grande precisão: "Progresso e barbárie estão hoje, como cultura de massa, tão enredados que só uma ascese bárbara contra esta última e contra o progresso dos meios seria capaz de produzir de novo a não-barbárie" (Adorno, 1993, p. 43).

\section{U ma nota, à guisa de conclusão}

A leitura de M inina moralia proporciona-nos a experiência do embate com a expressão das conseqüências das transformações sociais operadas pelo capitalismo tardio naquela esfera que soubera preservar sua imediatidade, a vida privada (D uarte, 1997). N esse belo livro, assim como em Educação após Auschwitz, encontramos um impulso inconformista com as condições objetivas e subjetivas do mundo administrado. Em meio a inúmeros exemplos da vida cotidiana - por vezes de sua própria biografia -, Adorno analisa os apuros do particular (D uarte, 1997), nos quais se podem ler seguidos lamentos pela perda da delicadeza de vários hábitos urbanos: entre outros, as viagens em trens antes luxuosos, 0 andar vagaroso pela cidade, 0 fechar cuidadoso das portas. Se estes foram hábitos aristocrático-burgueses e, portanto, exclusivistas, pelo menos expressavam a particularidade e a singularidade de um sujeito que ainda sobrevivia. Sob o mundo administrado e seus ardis reificadores, esse sujeito desapareceu, sem que houvesse outro para o seu lugar. Para Adorno, esse profundo embrutecimento do humano e a supressão de quaisquer traços de particularidade estão intimamente relacionados com 0 crescente processo de tecnificação das pessoas, 0 que por sua vez engendra uma certa pedagogia dos gestos e do corpo. N este sentido, lembrar os hábitos delicados, hoje bastante ausentes do nosso cotidiano, e o sujeito que Ihes dava voz, significa, talvez paradoxalmente, um movimento de resistência à barbárie e ao infortúnio.

$N$ esse contexto é possível pensar em processos de (des)subjetivação que se materializam na relação com o corpo, para os quais se desenvolve, nas malhas da socialização, uma pedagogia. Esta se faz presente nos esportes e nas aulas de Educação Física escolares, mas também nos momentos mais insuspeitos, como mostra Adorno. Isso nos autoriza a sugerir que a técnica mais refinada não necessariamente leva a um aumento das possibilidades humanas, mas, talvez leve, tendencialmente, a uma escravização do corpo por meio da incorporação dos processos reificadores da tecnificação. 
T écnica, corpo e coisificação: notas de trabalho sobre o tema da técnica...

Ao mesmo tempo, é preciso que se considere, como destacado ao longo deste texto, que o tema da técnica em Adorno está inscrito no contexto maior de crítica radical à racionalidade instrumental, que, ao fetichizar os meios, faz esquecer os fins. Se esta crítica dialética é radical, não pode ser vista como apocalíptica, saudosista ou passadista, um discurso que atribuiria à técnica a condição de algo "demoníaco", para a qual o único remédio seria dela livrar-se. Logo no prefácio de Dialética do es clarecimento, H orkheimer e Adorno (1985) advertem que, da mesma forma que não há dúvida de que a liberdade no âmbito da sociedade é inseparável do pensamento esclarecedor, também a idéia de progresso da humanidade não está dissociada do avanço dos meios ou dele pode prescindir. Afinal, dirá Adorno (1995b, p. 52): “(...) da funda até a bomba atômica, o progresso é escárnio satânico, mas que, somente na época da bomba atômica, é possível vislumbrar uma situação em que desaparecesse a violência do todo". Dito de outra forma, a própria crítica está, teimosamente, inscrita no próprio objeto sobre o qual se debruça.

\section{Recebido em outubro de 2006 e aprovado em novembro de 2006.}

\section{$\mathrm{N}$ otas}

1. Segundo M ax Horkheimer (1989, p. 40), "o próprio aparelho fisiológico dos sentidos do homem trabalha já há tempos detalhadamente nos experimentos físicos. A maneira pela qual as partes são separadas ou reunidas na observação registradora, o modo pelo qual algumas partes passam despercebidas e outras são destacadas, é igualmente resultado do moderno modo de produção, assim como a percepção de um homem de uma tribo qualquer de caçadores ou pescadores primitivos é o resultado das suas condições de existência, e, portanto, indubitavelmente também do objeto. Em relação a isso, poder-se-ia inverter a frase: as ferramentas são prolongamentos dos órgãos humanos, na frase: os órgãos são também prolongamentos das ferramentas". Esse fetichismo da técnica se encontra também no esporte e em seu caráter maquinal, inclusive no que se refere à indústria cultural: "O s dominados celebram a própria dominação. Eles fazem da liberdade uma paródia, na medida em que livremente se colocam a serviço da cisão, mais uma vez, do indivíduo com seu próprio corpo. Por meio dessa liberdade se confirma a injustiça - fundada na violência social - que mais uma vez se destina aos corpos escravizados. Funda-se aí a paixão pelo esporte, na qual os senhores da cultura de massa farejam o verdadeiro substrato para sua ditadura. É possível arvorar-se de senhor na medida em que a dor ancestral, violentamente repetida, mais uma vez é provocada em si mesmo e nos outros" (Adorno, 1997b, p. 328).

2. Sobre os rituais sadomasoquistas, em especial no ambiente universitário, consultar o instigante trabalho de Zuin (2002).

3. Se fosse obrigado a resumir a uma fórmula esse caráter manipulador, Adorno o denominaria consciência coisificada. Para ele, as pessoas desse tipo se tornam, por assim dizer, 
iguais a coisas. Em seguida, na medida em que conseguem, reduzem também os outros à condição de coisa. Exemplo claro disso seria a expressão fertigmachen, que goza de enorme prestígio entre os "valentões", assim como outrora entre os nazistas. Recorremos aqui à explicação cunhada por Giacóia Jr. (2001, p. 51): “Essa forma de ser, Adorno a ilustra com a intraduzível expressão fertigmachen (concluir/liquidar); essa expressão define os homens como coisa preparada, manipulada, e coisa danificada. A fórmula geral cunhada por Adorno para o tipo do caráter manipulatório - ainda que o faça apenas para fins de compreensão - é consciência reificada (verdinglichtes Bewusstsein)".

4. Vale lembrar o relato e a interpretação que fez $\mathrm{H}$ annah Arendt do julgamento de Adolf Eichmann, encarregado de organizar o envio de prisioneiros para os campos de concentração e extermínio no período nazista. Exemplo de consciência reificada para Adorno - e expressão da "banalidade do mal" para Arendt -, Eichmann inicialmente se considerou inocente perante as acusações de crime contra a humanidade e contra o povo judeu, justificando sua posição pelo fato de nunca haver matado qualquer prisioneiro com suas próprias mãos, mas apenas, como funcionário, ter seguido ordens administrativas. Seu advogado, por sua vez, nomeou as experiências de morticínio realizadas nos campos como de ordem "médica" (Arendt, 1992).

5. N a bela elaboração de Jürgen $\mathrm{H}$ abermas (1990, p. 139), Adorno corporificou de forma singular a alergia em relação a ela: "Para ele, a frieza representava o princípio da subjetividade burguesa, sem o qual Auschwitz não teria sido possível. D ecifrou, mesmo na normalidade mais insuspeita, a presença de uma vida sem calor. N essa hipersensibilidade, desenvolvida até o virtuosismo, não se anuncia, como suspeitara Bloch, o olhar malévolo do misantropo, mas o resíduo de uma ingenuidade não-exteriorizada e constantemente mobilizável".

6. No livro A teoria da classe ociosa, o americano Thorstein Veblen (1857-1929) formula a famosa tese sobre o consumo conspícuo, segundo a qual o consumo de bens teria, sob vários aspectos, servido, desde um estágio predatório da H istória até os dias de hoje, não para a satisfação das verdadeiras necessidades humanas, mas sim para a manutenção do prestígio social, do status de uma classe que se manteve fora da esfera da produção industrial, a classe ociosa. De acordo com Veblen, o plano de vida da classe ociosa é em grande parte uma herança do passado e por conta disso acaba incorporando muitos hábitos e ideais de um período primitivo bárbaro. Esse esquema bárbaro e arcaico - que remonta à idade da proeza e da vida predatória - também acaba se impondo às classes inferiores com maior ou menor grau. Segundo o autor, a expressão mais imediata e inequívoca da natureza humana arcaica na fase predatória é a propensão para a luta (Veblen, 1994, p. 111).

7. A interpretação do fenômeno esportivo como pertencente ao reino da ausência de liberdade aparece também em outros dois momentos: nos textos Tempo livre (Adorno, 2002, p. 112-127) e 0 esquema da cultura de massas (Adorno, 1997b, p. 328-329). N o primeiro texto, após problematizar o próprio uso da expressão em sua suposta oposição ao mundo do trabalho, assim como seu caráter fetichista, Adorno irá se referir ao esporte que, por meio da funcionalização do corpo, em nada se distingue da esfera do trabalho. $\mathrm{N}$ as suas palavras: "(...) mediante os esforços requeridos pelo esporte, mediante a funcionalização do corpo no 'team', que se realiza precisamente nos esportes prediletos, as pessoas adestramse sem sabê-lo para as formas de comportamento mais ou menos sublimadas que delas se esperam no processo de trabalho. A velha argumentação de que se pratica esporte para permanecer 'fit' é falsa só pelo fato de colocar a 'fitness' como fim em si; 'fitness' para o trabalho é contudo uma das finalidades do esporte. De muitas maneiras, no esporte, nós nos obrigaremos a fazer certas coisas - e então gozaremos como sendo triunfo da própria liberdade - que, sob a pressão social, nós temos de obrigar-nos a fazer e ainda temos de 
T écnica, corpo e coisificação: notas de trabalho sobre o tema da técnica...

achar palatável" (Adorno, 2002, p. 124). Em 0 esquema da cultura de massas - espécie de "anexo" da Dialética do esclarecimento que não prevaleceu na versão final - Adorno dá algumas indicacõoes para a compreensão do caráter estrutural do esporte na sociedade contemporânea, sobretudo no âmbito da indústria cultural, da racionalidade instrumental, da tecnologização do corpo e da produção da crueldade: "O s recordes, nos quais os esportes encontram sua realização, proclamam o evidente direito dos mais fortes, que emerge tão obviamente da concorrência, porque ela cada vez mais os domina. No triunfo de tal espírito prático, tão longe das necessidades de manutenção da vida, o esporte torna-se uma pseudopráxis, na qual os praticantes não mais podem agir por si mesmos, mas mais uma vez transformam-se em objetos, o que, na verdade, já são. Em sua literalidade sem brilho, destinada a uma gravidade (seriedade) brutal, que entorpece cada gesto do jogo, torna-se o esporte o reflexo sem cor da vida endurecida e indiferente. Só em casos extremos, que deformam a si mesmos, o esporte mantém o prazer do movimento, a procura pela libertação do corpo, a suspensão das finalidades" (Adorno, 1997b, p. 329; tradução nossa).

8. No aforismo Paysage, Adorno (1993, p. 41) também irá falar em alterações, mediadas pelas novas condições técnicas, no aparelho perceptível das pessoas, sobretudo no olhar. Ao referir-se à falta de expressividade das paisagens americanas, o autor destacará: "Ela [a paisagem] é desolada e desoladora. A isso corresponde a maneira de percebêla. Pois o que o olhar apressado viu apenas de dentro do automóvel não pode ser repetido e, como lhe fazem falta os traços, assim também desaparece sem deixar traços".

9. A relação de pura funcionalidade dos objetos atinge também o cenário par excellence da vida privada, do particular: a casa, como alerta Adorno (1993, p. 32) no aforismo Asilo para desabrigados: "A destruição das cidades européias, assim como os campos de trabalho forçado e de concentração, apenas dá prosseguimento, como executores, àquilo que o desenvolvimento imanente da técnica há muito tempo já decidiu acerca das casas. Estas são como latas de conserva velhas, só servem para ser jogadas fora".

\section{Referências}

AD O RN O, T.W. Zur Bekämpfung des Antisemitismus heute. In: ADORn O, T.W. Kritik: kleine Schriften zur G esellschaft. Frankfurt am M ain: Suhrkamp, 1971. p. 105-133.

AD O RN O, T.W. A indústria cultural. In: $\mathrm{CoHn}, \mathrm{G}$. (O rg.). Comunicação e indústria cultural. São Paulo: EDUSP, 1978. p. 363-371.

AD ORN O, T.W. M inima moralia: reflexões a partir da vida danificada. Trad. de Luiz Eduardo Bicca. São Paulo: Ática, 1993.

AD O RN O, T.W. Educação após Auschwitz. In: Ado orno, T.W. Educação e emancipação. Rio de Janeiro: Paz \& Terra, 1995a. p. 119-138.

AD O RN O, T.W. Progresso. In: Adorno, T.W. Palavras e sinais. modelos críticos 2. Petrópolis: Vozes, 1995b. p. 37-61. 
AD O RN O, T.W. Veblens Angriff auf die Kultur. Frankfurt am Main: Suhrkamp, 1997a. (G esammelte Schriften, 10, t. 1)

AD O RN O, T.W. D as Schema der M assenkultur. Frankfurt am M ain: Suhrkamp, 1997b. (Gesammelte Schriften, 3)

AD O RN O, T.W. Tempo livre. In: Adorno, T.W. Indústria cultural e sociedade. São Paulo: Paz \& Terra, 2002. p. 112-127.

ARENDT, H. Eichmann in Jerusalem: a report on the banality of evil. N ova York: Penguin, 1992.

BEN JAM IN , W. O bras escolhidas I: magia e técnica, arte e política. São Paulo: Brasiliense, 1985.

BEN JAM IN, W. Charles Baudelaire: ein Lyriker in Zeitalter des H ochkapitalismus. 7. ed. Frankfurt am M ain: Suhrkamp, 1997.

BRÜ SEKE, F.J. A crítica à técnica moderna. In: BRÜSEKE, F.J. A técnica e os riscos da modernidade. Florianópolis: UFSC, 2001. p. 115-182.

DUARTE, R. Adornos: nove ensaios sobre o filósofo frankfurtiano. Belo H orizonte: UFM G, 1997.

DUARTE, R. Adorno/H orkheimer \& A dialética do esclarecimento. Rio de Janeiro: Zahar, 2002.

H ABERM AS, J.T.W. Adorno: pré-história da subjetividade e autoafirmação selvagem. In: FreitAG, B.; RouAnet, S.P. H abermas. São Paulo: Ática, 1990. p. 139-150.

H ORKHEIMER, M. Teoria tradicional e teoria crítica. In: OS PENSAD ORES (Adorno e H orkheimer). São Paulo: Abril cultural, 1989.

H ORKHEIMER, M. Eclipse da razão. São Paulo: Centauro, 2000.

H ORKHEIM ER, M.; AD O RN O, T.W. D ialética do esclarecimento: fragmentos filosóficos. Rio de Janeiro: Zahar, 1985.

GIACÓ IA JUNIOR, O. Ética, técnica, educação. In: M ORAES, E.J.; BignotTo, N. (O rg.). H annah Arendt: diálogos, reflexões, memórias. Belo H orizonte: UFMG, 2001. p. 48-62.

M ARCUSE, H. O ne dimensional man. Boston: Beacon, 1966. 
T écnica, corpo e coisificação: notas de trabalho sobre o tema da técnica...

M ARCU SE, H. Tecnologia, guerra e fascismo. São Paulo: un Esp, 1999. M ARCUSE, H. A noção de progresso à luz da psicanálise. In: M ARCUSE, H. Cultura e psicanálise. São Paulo: Paz \& Terra, 2001. p. 112-138. VEBLEN, T. The theory of the leisure class. N ew York: D over, 1994. ZUIN, A.A. 0 trote na universidade: passagens de um rito de iniciação. Campinas: Autores Associados, 2002. 